\title{
Do We Need Taxi Counter at Major Transportation Hubs?
}

\author{
S. Arintono ${ }^{1 *}$, A. S. A. Alwosheel ${ }^{1}$, I. B. H. Alabri ${ }^{l}$ \\ ${ }^{I}$ Department of Civil Engineering, College of Engineering Al Imam Mohammad ibn Saud Islamic University \\ Riyadh, Saudi Arabia \\ *Email:SPArintono@imamu.edu.sa
}

\begin{abstract}
Taxi service at major international airport is usually an exclusive service where only those registered with the airport authority can serve passengers. Intending passengers need to register and pay a fixed fare at the taxi counter before using the service. Many customers complain that the fixed fare is significantly higher than if it was based on meter. This paper discusses the advantages and disadvantages of having taxi counter at major transportation hubs, the objective of which is to find the best solution for the benefit of all concerned parties: taxi drivers, customers and the authority. Data for analysis was obtained from observations at a number of airports and rail stations in Indonesia and Malaysia. Result of the analysis suggests that it is ideal to have taxi counter, but use of the service should be made possible without having the customers to visit the counter.
\end{abstract}

Keywords: taxi operation, taxi counter, airport taxi

Paper type: Research paper

\section{INTRODUCTION}

It is a common practice that at airports, either domestic or international, there are taxi counters where airline passengers who wish to use the service have to 'report' their intention prior to getting the service at the taxi bay. Normally, they have to pay the cost for the ride following a pre-set fare based on the estimated distance to the available destination zones on the list. Usually, the pre-set fare is higher compared to normal ride using the meter. Some of the reasons for the higher fare include administrative charges incurred by the airport authority for the service provision, and some safety factor for the assumed average distance to the zone, from the airport.

From user's point of view, the existence of taxi counter is less beneficial in terms that they have to spend extra time to visit the counter (rather than proceeding directly to the taxi bay) and higher charges based on the destination list. In addition, they have no option other than to accept the available taxi on their turn. From taxi driver's view on the other hand, they cannot get cash payment directly from the customers. Instead they have to claim the money from the airport authority using the taxi coupon (ticket), which means that they have to drive back to the airport to get paid.

Similar taxi operation system is also implemented at major transportation hubs other than airports, e.g. at rail stations, bus terminals, etc. The discussion in this paper attempts to find a suitable policy regarding taxi operation at major transportation hubs, exploring the advantages as well as the disadvantages of having taxi counters, exposing arguments from both sides, taxi drivers and customers alike, to answer the objective of proposing the best option in the provision of taxi counter at major transportation hubs.

\section{TAXI OPERATING CHARACTERISTICS}

Taxi operation at major transportation hubs, especially airports, can be either 'exclusive' or 'non-exclusive'. By exclusive means that only authorized taxi, those registered with the airport authority, can bring passengers in and out of the airport, other taxi can only bring passengers in but not out of the airport. Under non-exclusive taxi operation on the other hand, any taxi is allowed to convey passengers in and out of the airport. Example of the exclusive taxi operation is available at Kuala Lumpur International Airport (KLIA), Malaysia. Meanwhile, the Soekarno-Hatta International Airport (SHIA) in Jakarta, Indonesia, adopts the non-exclusive system.

Initially, at the Jakarta's SHIA, Bluebird, being the best in terms of customer's satisfaction, was the only taxi given privilege to run the airport taxi service. Instead of applying pre-set fare to several major destinations within and outside Jakarta, passengers had to pay 'airport charge' first, then additional payment was applicable based on the taxi-meter and highway toll charges. This exclusive right to Bluebird was considered by other taxi companies as being unfair, since they could not enjoy the benefit from the huge demand of the airport taxi service.

The airport taxi operation system was then modified. SHIA was opened to any taxi to bring passengers in and out of the airport. Other arrangement remains unchanged, i.e. passengers had to pay the airport charge in addition to the distance-based charge shown by the taxi-meter and highway toll charges. However, the new system did not satisfy customers in some ways. First, they did not have a choice other than taking the first taxi available to them. Second, the service qualities are not equal amongst taxi companies, e.g. taxi-meters not running properly, old and 
uncomfortable vehicles, unpleasant behavior of the drivers, etc. In fact, Bluebird was still voted as the best by many in the region. So then customers complained, demanding to have a choice to which taxi they like to ride. Finally, the operating arrangement was once again changed. Currently, all taxi companies operating at the airport has their own queue line, and so intending passengers have freedom to select taxi of their choice. Throughout these changes in the airport taxi operation at SHIA, one thing remains unchanged: passengers go directly to the taxi queuing at the bay, no need to register at the counter prior to taking the ride. Taxi counters are available, but they are for those who require VIP service with premium fare.

In KLIA it is the exclusive system which prevails, as discussed in [1] and [2]. There, intending passengers have to visit the taxi counter first, pay the cost for the ride following a pre-set fare based on the available destination zones, and only then they can go to the taxi bay to get the service. Taxi drivers claim the fare paid by customers using the portion of the ticket they get from passengers, subject to some deduction for the 'management fee'. Due to the excessive number of airport taxi operating in KLIA, each driver has to wait long time and can only make limited number of trips carrying passengers per day from KLIA, implying further, limited income.

In Putrajaya Sentral, an intermodal station linking various modes of public transport (rail, bus, and taxi) as well as private vehicle (it is a park and ride facility), taxi customers, as in KLIA, have to register in the counter and pay the cost for the intended ride before they can use the taxi, as described in [3] and [4]. The difference is that, in Putrajaya Sentral, any taxi can bring passengers in and out of the station, since the operating system is non-exclusive. Because of the shorter length of queue, taxi driver's waiting time in this hub is not as excessive as in KLIA.

In Bandar Tasik Selatan (BTS) Light Rail Transit (LRT) station however, following [5] and [6], there is no taxi counter. Therefore, intending passengers feel free to get the service directly from the taxis queuing at the bay. At this particular station, any taxi is allowed to carry passenger(s) in and out of the station. Similar practices (with or without counter, exclusive or non-exclusive) are available in other transportation hubs throughout the country. There seems to be no standard as to which type of facility (airport, railway station, bus terminal, etc.) or size of the facility (large, medium, small) should or should not have taxi counter. But those facilities adopting exclusive operation always have taxi counter, and at those with no counter, taxi operation is always non-exclusive. Table 1 shows summary of the findings about the nature of taxi provision and operation at a number of major transportation hubs in Indonesia and Malaysia.

Table 1. Taxi Provision at Major Transportation Hubs

\begin{tabular}{lccc}
\hline \multicolumn{1}{c}{ Name of Facility } & Type of Facility & Taxi Counter & Remarks \\
\hline Kuala Lumpur International Airport & Airport & Available & Exclusive operation \\
$\begin{array}{l}\text { Putrajaya Sentral } \\
\text { Bandar Tasik Selatan }\end{array}$ & Park and Ride & Available & Non-exclusive \\
$\begin{array}{l}\text { Soekarno-Hatta International } \\
\text { Airport }\end{array}$ & Rail Station & Not available & $\begin{array}{c}\text { Non-exclusive } \\
\text { Adisucipto International Airport }\end{array}$ \\
$\begin{array}{l}\text { Gambir } \\
\text { Ambarukmo Plaza }\end{array}$ & Airport & Available & $\begin{array}{c}\text { Non-exclusive, counter only } \\
\text { for premium taxi }\end{array}$ \\
& Rail Station & Available & Exclusive operation \\
Shopping Center & Not available & Exclusive operation \\
\end{tabular}

\section{PASSENGER'S POINT OF VIEW}

Taxi customers (passengers), based on their origins, can be divided into local resident and non-resident, with local residents having knowledge of the localities, e.g. existing road networks and geographical positions of the origin and destination of the intended trips. Therefore, the former has advantage over the later in estimating the cost of travel when using taxi.

In Malaysia normally taxi passengers pay the service based on meter, especially in major cities (Kuala Lumpur, Johor Bahru). But in smaller towns (Kuantan, Kuala Terengganu) the taxi has no meter, so passengers have to bargain for the fare. In addition, even if there is meter, and haggling is officially prohibited, some drivers are reluctant to use the meter, demanding fixed price to be agreed before starting the trip, especially when there is long queue of taxi waiting for passengers at the airport or other important traffic generators. The other unexpected behavior of taxi drivers is that, if they know that the customer is a non-resident, therefore having little or no knowledge about the road network, some of them will drive through longer route to get to the destination, to generate higher fare on the meter.

Naturally, taxi service is more popular among non-residents for convenience and safety, while the majority of local residents either drive their own vehicles or select bus rather than taxi for cost saving, especially for regular mandatory trips under fair weather conditions. Therefore, it is logical that most taxi drivers prefer to ply for hire at major transportation hubs (airports, rail stations, bus terminals, hotels and tourist spots). 
For local customers who are familiar with the road network between origin and destination points, it is more beneficial to choose a metered taxi rather than bargaining for the fare which usually ends up at higher fare compared to meter. On the other hand, since dishonest drivers often cheat their customers to get higher fare by the meter, nonresidents are better off by bargaining for a fixed price before the ride. The problem is, these non-resident customers may not know how much the reasonable fare should be. In other words, the presence of taxi counter is good, that they do not need to bargain to achieve the reasonable fare level. Under such circumstances, using the same analogies regarding taxi services at the airports and other major transportation hubs, this is the preferable option from passenger's point of view.

Local residents prefer metered taxi over fixed fare bargain, which means that the presence of taxi counter is a nuisance to them in terms that they have to spend extra time to visit the counter, and then, finally, they still have to pay higher fare either by meter or bargaining. However, for non-resident the presence of taxi counter is clearly beneficial, otherwise they shall be worse off in the following ways: getting higher fare on meter because of the indirect route or bargain fare much higher than normal because they are not familiar with the route network and geographical positions of the origin and destination.

\section{DRIVER'S POINT OF VIEW}

The interest of a taxi driver is to maximize traveled distance carrying passenger(s) and minimize empty travel distance, to maximize profit. As such, each time after finishing one trip conveying customer to the destination, they will drive the vehicle to the nearest point where they can expect to get the next customer. Common preferences include airport, railway station, bus station, shopping malls, hotels, etc. Depending on the length of queue at the respected location, they may decide either to join the queue or cancel queueing and move to other location while searching for potential customer along the roads.

At transportation hubs without taxi counter customer directly approaches taxi queueing at the bay, and then the trip starts immediately either on meter or bargain fare. By default, the trip will go through the shortest possible route known by the driver or on customer's request, who may have better knowledge of the route network and traffic conditions. When the trip ends the customer will pay for the trip either based on meter or the agreed fare whichever is the case. This type of direct payment is the primary option for taxi drivers, and so that they can instantly spend the money for anything related to working as taxi driver (food, parking, gasoline, maintenance, etc.).

On the other hand, at transportation hubs with taxi counter, customers pay for the ride through the counter, which issues ticket to be partially handed over to the taxi driver before or after the trip. The driver then has to claim the money from the respected authority later after the trip. It means that it is not possible to get the money directly in cash. Instead, they have to drive back to the airport or station (in some cases without carrying passengers) to claim, subject for deduction by the authority in charge. Clearly, it is a waste of resources (time, effort, energy, etc.) which could otherwise be saved under 'no taxi counter' policy.

For an average taxi driver who prefers to offer service to customers with honesty, there seems to be no difference between driving taxi with or without meter, the final earning will be more or less the same. But the existence of taxi counter at transportation hubs may slightly reduce their effective driving time and income as well due to the necessity to 'driving empty back to the airport' to collect payment from earlier customer. However, to the other type of driver, if any, who choose to maximize profit, by cheating their customers if necessary (e.g. by taking longer route than it should), in both cases, with or without meter, there are perfect excuses to overcharge the non-resident customers. In this case, the presence of taxi counter is good to avoid customers from being exploited by dishonest taxi drivers.

\section{THE BEST OPTION}

As discussed earlier, the presence of taxi counter is good to protect non-resident customers against overcharging usually practiced by dishonest taxi drivers. Resident customers however, most probably, are more inclined towards 'no taxi counter' option which can save time and cost. In addition, non-resident customers who are not on their first trip to the place, and therefore already have sufficient knowledge about the road network and the reasonable fares, may also prefer direct approach without having to go through the counter.

On the taxi driver's side, those who are honest or dishonest, irrespective of whether payment is based on meter or bargaining, the only difference between 'with taxi counter' and 'without taxi counter' is about direct cash (without counter) and delayed cash (with counter) plus the need to drive back to the 'airport' to claim the money. Therefore, it is clear that, logically, the majority of taxi drivers may opt for 'without counter' which is more beneficial for them.

Considering that the authorities in charge should accommodate the interests of both parties, customers and drivers alike, the best option could be that we should have both options in our major transportation hubs. Those who are confident enough about where to go, how to get there, and how much it will cost, should be free to access the taxi service directly, without having to go through the counter. On the other hand, for those who are on their first visit to the country or place, having no or little knowledge about the best mode, route and/or cost, the availability of taxi counter is a great help. In practice, both types of customers (resident and non-resident, with ticket or no-ticket from taxi counter) can be served in a single queue line. This is applicable only for taxi service based on meter. For 
taxi without meter, in order that the operation is in good order, it is desirable to have counter at major transportation hubs, for passengers and drivers to queue properly.

More recently, the emergence of the application-based online taxi services (e.g. Uber, Grab, Go Car) where customers and drivers virtually meet online is an excellent solution for all (drivers, passengers and authorities at once). There, customers have opportunity to view the available options (comparing fares among operators) prior to making the trip, with no surcharge to be paid to the authority. Online taxi drivers are also benefitted that they do not need to wait in a long queue to get a customer irrespective of the level of demand and supply, since the system takes over the assignment to serve customers, which is not necessarily based on first-in-first-out rule. The airport authority in turn, does not need to provide facilities (space, equipment, man power, office supplies) to run a 'taxi counter' other than an open space for the 'meeting point' between passengers and the online taxi.

Unfortunately, not all authorities, either within the same region or country, welcome online taxi to operate under their roofs. Refusal also comes from conventional taxi operators whose market share has dropped significantly due to the presence of the online taxi. On the other hand, however, customer's preference has shifted towards online taxi because it is more convenient, comfortable, cheaper and safe. To improve customer's satisfaction further, online taxi should be made available also at major transportation hubs.

\section{CONCLUSIONS}

From the view point of both taxi drivers and passengers with knowledge of the local area, the existence of taxi counter is not important and is therefore less preferred. However, for non-resident customers, particularly those who are on their first trips, it is necessary to provide taxi counter to protect them from being exploited by dishonest taxi drivers. Customers shall be better off if both options are available at major transportation hubs (airports, railway stations, bus terminals, etc.).

The online taxi service is superior compared to the conventional one in the sense that: i) the fare to be paid by customer is cheaper and can be accessed prior to making the trip; ii) customer has the right to select the service provider based on fare and rating comparison; iii) taxi drivers do not need to queue to get an order irrespective of the level of supply and demand for the service since the online application system takes over this task, iv) the local authority does not need to provide facilities for taxi counter since passengers and drivers have 'met' online. Therefore, ideally, online taxi should be made available at all major transportation hubs.

\section{REFERENCES}

[1] S. Arintono, H. Hamid and S. W. Yin, Taxi Driver's Waiting Time Case Study at Malaysian Low-Cost Carrier Terminal, World Engineering Congress 2010, Kuching, Sarawak, Malaysia, 2-5 Aug 2010.

[2] Soo Wan Yin (2009), Analysis of the taxi driver's waiting time case study at LCCT (Low Cost Carrier Terminal), unpublished Bachelor of Engineering (Civil) Project Report, Department of Civil Engineering, Faculty of Engineering, Universiti Putra Malaysia, Malaysia.

[3] Chuah Pooi Yee, Sulistyo Arintono and Hussain Hamid, Times Spent in Driving Taxi Case Study in Putrajaya Sentral, Proceeding of the Malaysia University Transportation Research Forum and Conference (MUTRFC), Universiti Tenaga Nasional, Bangi, Malaysia, 21 Dec 2010.

[4] Chuah Pooi Yee (2009), Analysis of taxi driver's waiting time case study at Putrajaya Sentral, unpublished Bachelor of Engineering (Civil) Project Report, Department of Civil Engineering, Faculty of Engineering, Universiti Putra Malaysia, Malaysia.

[5] Sulistyo Arintono, Characteristics of Taxi Operation at Bandar Tasik Selatan Rail Station, Proceeding of the 18th Inter-University Forum for Transportation Studies, University of Lampung, August 2015.

[6] Kang, W. W., 2009, Analysis of Taxi Driver's Waiting Time Case Study in Bandar Tasik Selatan, unpublished Bachelor of Engineering (Civil) Project Report, Department of Civil Engineering, Faculty of Engineering, Universiti Putra Malaysia. 